\title{
Discussing an uncertain future: end-of-life care conversations in chronic obstructive pulmonary disease. A systematic literature review and narrative synthesis
}

\author{
Natalie Momen, ${ }^{1}$ Peter Hadfield, ${ }^{2}$ Isla Kuhn, ${ }^{3}$ Elizabeth Smith, ${ }^{4}$ \\ Stephen Barclay ${ }^{4}$
}

- Additional materials are published online only. To view these files please visit the journal online (http://dx.doi.org/ 10.1136/thoraxjnl-2012201835).

${ }^{1}$ NIHR CLAHRC for Cambridge and Peterborough, Institute of Public Health, University of Cambridge, Cambridge, UK

${ }^{2}$ North Street Medical Practice, Peterborough, UK

${ }^{3}$ University of Cambridge Medical School Library, School of Clinical Medicine, Cambridge, UK

${ }^{4}$ General Practice and Primary Care Research Unit, Department of Public Health and Primary Care, Institute of Public Health, University of Cambridge, Cambridge, UK

\section{Correspondence to} Dr Stephen Barclay, General Practice and Primary Care Research Unit, Department of Public Health and Primary Care, University of Cambridge, Institute of Public Health, Robinson Way, Cambridge CB2 OSR, UK;

sigb2@medschl.cam.ac.uk

Received 7 March 2012 Accepted 7 June 2012

Published Online First

16 July 2012
ABSTRACT

Background Guidelines recommend open discussions between patients and healthcare professionals as the end-of-life (EOL) approaches. Much of the knowledge about the EOL is based on the needs of patients with cancer and the applicability of this to other diseases is often queried. A literature review was undertaken concerning EOL care (EOLC) conversations in chronic obstructive pulmonary disease (COPD)

Design A systematic literature review and narrative synthesis obtained papers reporting on EOLC conversations between patients with COPD and their healthcare professionals with respect to the prevalence of conversations; each party's preferences for timing and content; and the facilitators and blockers. Inclusion criteria were articles published in peer-reviewed journals, written in English, reporting studies of adult patients with COPD and/or their healthcare professionals concerning discussions of care at the EOL.

Results 30 papers were identified. Most patients reported that they have not had EOLC discussions with healthcare professionals. While many patients would like these conversations, a potentially large minority would not; the proportions varied among studies. Healthcare professionals find these discussions difficult and many prefer patients to initiate them.

Conclusions Patients' preferences for EOLC conversations vary greatly. Healthcare professionals need to respect the wishes of those not wanting to discuss EOLC and provide multiple opportunities for those who do wish to have these discussions. Recommendations on how to approach the conversation are made.

\section{INTRODUCTION}

Chronic obstructive pulmonary disease (COPD) is a progressive, incurable lung disease punctuated by acute exacerbations that are characterised by airflow obstruction caused by chronic inflammation. ${ }^{1}$ It is estimated that by 2020 , COPD will be the third leading cause of death worldwide. ${ }^{2}$

Patients with advanced COPD need palliation of symptoms, such as breathlessness and anxiety, throughout the long duration of their illness. Endof-life care (EOLC) focuses more on the final stages of the illness and has been defined as care that 'enables the supportive and palliative care needs of

\section{Key messages}

What is the key question?

- What is the prevalence of conversations about end-of-life care between patients with chronic obstructive pulmonary disease (COPD) and their healthcare professionals?

- What are each parties' preferences for their timing and content?

-What are the facilitators and blockers?

What is the bottom line?

- Although a substantial minority of patients with COPD do not want end-of-life care conversations with their healthcare professionals, most do but are not being given the opportunity to have such a discussion due to a wide range of barriers.

\section{Why read on?}

- COPD is a leading cause of death. This paper discusses the implications of avoidance of conversations and makes recommendations on how they might be approached.

patient and family to be identified and met throughout the last phase of life and into bereavement.' $^{3}$ Prognostication in COPD is, however, challenging: death often occurs 'before the patient is perceived as being "terminal". 4 Many patients die 'with', rather than 'of', COPD: causes of death include respiratory (35\%), cardiovascular (26\%), cancer $(21 \%)$ and other $(18 \%){ }^{5}$ The best current prognostic model is the BODE Index, which is better at predicting death than forced expiratory volume in $1 \mathrm{~s}\left(\mathrm{FEV}_{1}\right)$ alone. ${ }^{6}$ As with all such models, this is of some use with groups of patients but of little help with individuals. The consequence is often a 'prognostic paralysis'; and because prognosis is so uncertain EOLC issues are not addressed. $^{7}$

The palliative and EOLC needs of people living with COPD have only recently been recognised in health policy, the previous focus being on active disease management. The National Institute for Health and Clinical Excellence stated in its 2004 COPD guideline ${ }^{1}$ that the full range of palliative care services should be offered to people with 
COPD'. The American Thoracic Society stated that palliative care should be available throughout all stages of illness. ${ }^{8}$ The National Institute for Health and Clinical Excellence highlighted the need to involve multidisciplinary palliative care teams in advanced COPD. ${ }^{9}$

The UK NHS EOLC strategy ${ }^{3}$ calls for open discussions between healthcare professionals (HPs) and patients as the endof-life (EOL) approaches. This is the first step of the 'EOLC pathway', 3 to ensure well planned care is delivered. Patient knowledge that death is approaching and of what can be expected is seen as a prerequisite of a 'good death'. ${ }^{10}$ Concern has been expressed that EOLC policy and services are based on the needs of patients with cancer, which has a clearer terminal phase: uncertainty over the extent to which a cancer model for EOLC fits with the unpredictable course of COPD has stimulated this review.

EOLC conversations are not taking place as policy recommends in COPD. ${ }^{11}{ }^{12} \mathrm{HPs}$ are more likely to have such discussions with patients with cancer than those with COPD. ${ }^{13}$ This is despite frequent contact providing multiple opportunities for discussions: of those hospitalised with an exacerbation, 74\% see their general practitioner (GP) in the month before admission, $31 \%$ three or more times. ${ }^{14}$

A 2011 BMJ editorial highlighted the need to establish how patients with COPD will respond to EOLC discussions and their appropriate timing. ${ }^{15}$ We seek to address these issues in the first systematic literature review of the attitudes of patients with COPD, and those of their HPs.

\section{METHODS}

The search aimed to identify all papers reporting studies of adult patients with COPD and/or their HPs concerning EOLC discussions in Medline, PsycINFO and CINAHL that were written in English and published in peer-reviewed journals, concerning:

1. the prevalence of conversations;

2. the preferences of patients with COPD and HPs for the timing and content of conversations;

3. the barriers and facilitators to conversations.

The exclusion criteria and process for the literature search, search strategy (box 1 in online supplement), paper selection and the narrative synthesis are described in the online supplement to this paper.

\section{RESULTS}

The search strategy was complex and generated a large number of titles. After screening and discussion by reviewers (figure 1), 29 papers were found that met the inclusion criteria. One additional paper ${ }^{16}$ was found when hand-searching Chest, electronically published ahead of print. In total, 30 papers were included (see table 1 in online supplement).

A summary of the findings is presented below. The online supplement presents the results in greater detail.

\section{Are these discussions taking place?}

A minority of patients report having discussed EOLC with their HPs. HPs confirm this. They 'very rarely initiate' EOLC discussions as described in the NHS EOLC strategy ${ }^{3} 12$ and agree that prognosis and dying are infrequently discussed. ${ }^{17}$

\section{Patient attitudes towards EOLC discussions}

Studies report a range of patients to want more information about their illness and the future. Some want all available

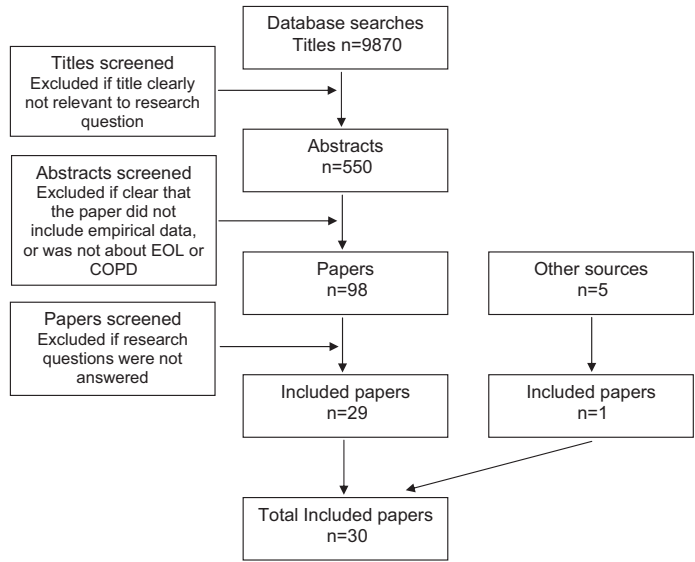

Figure 1 Flow diagram. COPD, chronic obstructive pulmonary disease $E O L$, end of life.

information to enable planning ahead. ${ }^{18} 19$ Around half of patients, however, do not want further information, ${ }^{20} 21$ citing the potentially distressing nature. ${ }^{20}$

\section{Patient preference for timing of discussions}

The limited literature concerning timing indicates a patient preference to wait until COPD is advanced. $^{22} 23$

\section{HP attitudes towards EOLC discussions}

HPs face a dilemma. While the majority view these discussions as necessary, ${ }^{13} 2425$ they believe only a minority of patients want to know their prognosis and it is difficult to recognise who these individuals are. ${ }^{13} 24$ HPs are concerned that such discussions may create anxiety or destroy hope. ${ }^{1326}$ Many doctors find conversations initiated by patients easier ${ }^{25} 26$ but admit to feeling uncomfortable even when patients ask about EOLC directly. ${ }^{26}$

\section{HP preference for timing of discussions}

HPs are unsure when to initiate EOLC conversations. In practice, HPs report that discussions often take place when the patient's health has deteriorated ${ }^{25}$ and they may be too unwell to make decisions. ${ }^{12}$ While some suggest discussions should be early in the illness, ${ }^{25}$ in practice this rarely occurs; only a small minority of GPs initiate discussions early on. ${ }^{12}$

\section{Barriers, cues and facilitators to EOLC discussions}

A wide range of barriers were identified, such as the difficultly in prognostication in COPD which leads to uncertainty over when discussions should begin ${ }^{12} 2627$; and the poor understanding of COPD among the general public. ${ }^{12} 1826$ Additionally, many HPs do not identify EOLC discussions as their responsibility. A good rapport with the patient, ${ }^{12} 28$ experience in dealing with EOLC matters, ${ }^{28}$ adequate training in breaking bad news ${ }^{12}$ and specialist knowledge ${ }^{12} 28$ are seen as particularly important.

\section{DISCUSSION}

\section{Principal findings}

Conversations about EOLC are rare in COPD. Patient preference varies: some want all available information, while others wish to avoid potentially distressing conversations. HPs acknowledge the value of conversations but find them difficult, recognising that not all patients want these conversations. There are numerous barriers and each party prefers that the other initiates 
the discussion. Patients' preferences are mainly for discussions when disease is advanced; in practice they usually occur late in the disease course (if at all) when there is greater 'certainty', though patients are less able to participate. Three previous non-systematic reviews ${ }^{29-31}$ found a similar prevalence for conversations and planning.

\section{Strengths and weaknesses of this study}

Although the search strategy used only the three most pertinent databases, it appears to have been effective. Additional searches identified only one further paper, electronically published ahead of print. Only English language papers were included: most are from the UK or USA, with fewer from Canada, New Zealand or Europe. Additionally, unpublished data and the grey literature were not included.

The literature is relatively recent; only three papers were published before 2000. Studies presented a uniform picture with regards to the prevalence of conversations. The data concerning patient preferences were more diverse, partly due to studies investigating a variety of aspects of EOLC conversations, and the diversity of patient samples and disease severity.

\section{Explanations and implications}

There are many patients living with the life-limiting illness of COPD who are not being given the opportunity to discuss its progression, their future care and the EOL. A range of barriers inhibit these discussions.

Not all patients wish to have such conversations. ${ }^{32}$ Some may feel they do not have EOLC needs, preferring to focus on management of the disease and its symptoms, having lived with it for years. ${ }^{33}$ Patients not wishing to discuss EOLC preferences are often those who estimate their prognosis to be excellent, report quality of life to be good and do not desire active involvement in decision making. ${ }^{34} \mathrm{HPs}$ are rarely able to predict individuals' EOLC preferences, ${ }^{30}$ including preferences for discussions.

Additionally, patients' understanding of COPD as a lifelimiting disease is poor; when stating preferences for further information they may be unaware of the implications of such discussions. Patients often see COPD 'not so much as an illness, more a way of life' with attitudes to death comparable to those 'in a normal elderly population'. ${ }^{27}$

One major barrier is the uncertainty of prognosis creating difficulty in providing patients with information on the likely future course of their illness. Discussions might usefully cover explanation of the functional decline common in COPD, the possibility of fatal exacerbations and the potential for cardiovascular and other causes of death, including sudden death. ${ }^{29}$

No single group of HPs felt that their roles, relationships with patients or work settings made them the most appropriate HPs to have EOLC conversations. The NHS EOLC strategy emphasises the importance of multidisciplinary involvement ${ }^{3}$ : while these conversations are a 'collective responsibility', ${ }^{28}$ held on multiple occasions, the danger remains that no HP takes the responsibility.

Ensuring that patients who wish to discuss EOLC have the opportunity to do so is challenging. Practitioners and healthcare systems need to address the wide range of barriers that exist, for example, more time is required for consultations or training of healthcare professionals to have these difficult conversations. However, discomfort around the subject of EOL and the uncertainty and difficulties in prognostication are likely to remain.

HPs frequently worry that EOLC discussions may remove hope, ${ }^{13} 16^{26}{ }^{31}$ however avoidance of discussions may give false
Box 1 Suggested approach to end-of-life care conversations in chronic obstructive pulmonary disease

Respect autonomy: allow the patient to decide whether to have an end-of-life care conversation, when and with whom.

Patient centred: content, timing and pace set by the patient. Multiple opportunities: for the patient to explore issues if they wish.

Maintain balance: combine realistic hope with practical planning. Honest information: including acknowledgement of uncertainty. Document discussion: enable other healthcare professionals to be aware of the patient's preferences for care.

hope and deny patients the opportunity to prepare and plan. A balance needs to be struck between optimism and realism: 'I encourage you to hope for and expect the best, but it is also wise to prepare for the worst'. ${ }^{35}$ To maintain hope, HPs need to give patients time to get used to their poor prognosis, 'redirecting' them from hope for recovery to hope for quality time and a comfortable death. ${ }^{19}$

How to do that in practice remains a considerable challenge (box 1). As Sir William Osler wrote, 'If it were not for the great variability among individuals, medicine might as well be a science and not an art'

Contributors The study was designed and led by SB, literature searching was undertaken by NM, ES and IK, screening of abstracts and papers by NM, PH, SB and $\mathrm{ES}$, data extraction by NM and PH, journal hand-searching by $\mathrm{NM}$ and $\mathrm{PH}$, and synthesis by NM, PH and SB. All the authors have contributed to writing the paper. SB is the guarantor.

Funding This study was funded by the NIHR CLAHRC (Collaborations for Leadership in Applied Health Research and Care) for Cambridgeshire and Peterborough and Macmillan Cancer Support: their support is gratefully acknowledged. The opinions expressed are those of the authors not the funders.

\section{Competing interests None.}

Provenance and peer review Not commissioned; externally peer reviewed.

Data sharing statement We would be prepared to share data extraction sheets.

\section{REFERENCES}

1. National Institute for Health and Clinical Excellence. Chronic Obstructive Pulmonary Disease: Management of Chronic Obstructive Pulmonary Disease in Adults in Primary and Secondary Care. London: National Institute for Health and Clinical Excellence, 2010

2. Murray CJ, Lopez AD. Alternative projections of mortality and disability by cause 1990-2020: Global Burden of Disease Study. Lancet 1997:349:1498-504.

3. Department of Health. End of Life Care Strategy-Promoting High Quality Care for All Adults at the End of Life. London: Department of Health, 2008.

4. Murray SA, Pinnock H, Sheikh A. Palliative care for people with COPD: we need to meet the challenge. Prim Care Respir J 2006;15:362-4.

5. McGarvey LP, John M, Anderson JA, et al. Ascertainment of cause-specific mortality in COPD: operations of the TORCH Clinical Endpoint Committee. Thorax 2007:62:411-15.

6. Celli BR, Cote CG, Marin JM, et al. The body-mass index, airflow obstruction, dyspnea, and exercise capacity index in chronic obstructive pulmonary disease. N Engl J Med 2004;350:1005-12.

7. Murray SA, Boyd K, Sheikh A. Palliative care in chronic illness. BMJ 2005; 330:611-12.

8. Lanken PN, Terry PB, Delisser HM, et al. An official American Thoracic Society clinical policy statement: palliative care for patients with respiratory diseases and critical illnesses. Am J Respir Crit Care Med 2008;177:912-27.

9. National Institute for Health and Clinical Excellence. Quality Standard for Chronic Obstructive Pulmonary Disease. London: National Institute for Health and Clinical Excellence, 2011.

10. Smith R. A good death. An important aim for health services and for us all. BMJ 2000;320:129-30.

11. Gardiner C, Gott M, Small N, et al. Living with advanced chronic obstructive pulmonary disease: patients concerns regarding death and dying. Palliat Med 2009;23:691-7. 
12. Gott M, Gardiner C, Small N, et al. Barriers to advance care planning in chronic obstructive pulmonary disease. Palliat Med 2009;23:642-8.

13. Elkington $\mathbf{H}$, White $P$, Higgs $\mathrm{R}$, et al. GPs' views of discussions of prognosis in severe COPD. Fam Pract 2001:18:440-4.

14. The Royal College of Physicians of London, , British Thoracic Society and British Lung Foundation. Report 5 of the National Chronic Obstructive Pulmonary Disease Audit 2008: Survey of COPD Care within UK General Practices. London: Royal College of Physicians, 2008

15. Thorns A, Cawley D. Palliative care in people with chronic obstructive pulmonary disease. BMJ 2011;342:d106.

16. Au DH, Udris MU, Engelberg RA, et al. A randomized trial to improve communication about end-of-life care among patients with COPD. Chest 2012;141:726-35.

17. Janssen DJ, Spruit MA, Schols JM, et al. A call for high-quality advance care planning in outpatients with severe COPD or chronic heart failure. Chest 2011;139:1081-8.

18. Robinson T. Living with severe hypoxic COPD: the patients' experience. Nurs Times 2005;101:38-42.

19. Curtis JR, Wenrich MD, Carline JD, et al. Patients' perspectives on physician skill in end-of-life care: differences between patients with COPD, cancer, and AIDS. Chest 2002;122:356-62.

20. Gore JM, Brophy CJ, Greenstone MA. How well do we care for patients with end stage chronic obstructive pulmonary disease (COPD)? A comparison of palliative care and quality of life in COPD and lung cancer. Thorax 2000;55:1000-6.

21. Jones I, Kirby A, Ormiston P, et al. The needs of patients dying of chronic obstructive pulmonary disease in the community. Fam Pract 2004;21:310-13.

22. Gysels $\mathbf{M}$, Higginson IJ. The experience of breathlessness: the social course of chronic obstructive pulmonary disease. J Pain Symptom Manage 2010;39:555-63.

23. Gaber KA, Barnett M, Planchant $Y$, et al. Attitudes of 100 patients with chronic obstructive pulmonary disease to artificial ventilation and cardiopulmonary resuscitation. Palliat Med 2004;18:626-9.
24. Mulcahy P, Buetow S, Osman L, et al. GPs' attitudes to discussing prognosis in severe COPD: an Auckland (NZ) to London (UK) comparison. Fam Pract 2005;22:538-40.

25. Sullivan KE, Hebert PC, Logan J, et al. What do physicians tell patients with end-stage COPD about intubation and mechanical ventilation? Chest 1996;109:258-64.

26. Crawford A. Respiratory practitioners' experience of end-of-life discussions in COPD. Br J Nurs 2010;19:1164-9.

27. Pinnock H, Kendall M, Murray SA, et al. Living and dying with severe chronic obstructive pulmonary disease: multi-perspective longitudinal qualitative study. BMJ 2011;342:d142.

28. Halliwell J, Mulcahy P, Buetow S, et al. GP discussion of prognosis with patients with severe chronic obstructive pulmonary disease: a qualitative study. $\mathrm{Br} J \mathrm{Gen}$ Pract 2004;54:904-8

29. Heffner JE. Advance care planning in chronic obstructive pulmonary disease: barriers and opportunities. Curr Opin Pulm Med 2011:17:103-9.

30. Pfeifer M. End-of-life decision-making: special considerations in the COPD patient. MedGenMed 1999;3. http://www.medscape.com/viewarticle/408735. [formerly published in Medscape Pulm Med ejournal 1998;2(5)].

31. Curtis JR. Palliative and end-of-life care for patients with severe COPD. Eur Respir $J$ 2008:32:796-803.

32. Barclay S, Case-Upton S. Knowing patients' preferences for place of death: how possible or desirable? Br J Gen Pract 2009;59:642-3.

33. White $\mathbf{P}$, White $\mathrm{S}$, Edmonds $\mathbf{P}$, et al. Palliative care or end-of-life care in advanced chronic obstructive pulmonary disease: a prospective community survey. $\mathrm{Br} \mathrm{J}$ Gen Pract 2011;61:e362-70.

34. Hoffman J, Wenger N, Davis R, et al. Patient preferences for communication with physicians about end-of-life decisions. Ann Intern Med 1997;127:1-12.

35. Back AL, Arnold RM, Quill TE. Hope for the best, and prepare for the worst. Ann Intern Med 2003:138:439-43.

\section{Thorax alerts}

Sign up for our electronic table of contents alerts and you will never miss new issues of Thorax when published online. Stay ahead and up to date by visiting thorax.bmj.com. 